\title{
THE EFFECTS OF RETURNING FARMLANDS TO FORESTS OR PASTURES ON SOIL ANIMAL DIVERSITY AND ITS REGIONAL DIFFERENTIATION CHARACTERISTICS IN CHINA: A META-ANALYSIS
}

\author{
GAO, B. ${ }^{1,2}-$ WU, D. H. ${ }^{1,3,4^{*}}$ \\ ${ }^{1}$ College of Earth Science, Jilin University, Changchun, China \\ ${ }^{2}$ School of Tourism and Geography Science, Baicheng Normal University, Baicheng, China \\ ${ }^{3}$ Key Laboratory of Wetland Ecology and Environment, Northeast Institute of Geography and \\ Agroecology, Chinese Academy of Sciences, Changchun, China \\ ${ }^{4}$ School of Environment, Northeast Normal University, Changchun, China \\ ${ }^{*}$ Corresponding author \\ e-mail: wudonghui@iga.ac.cn
}

(Received 20 $0^{\text {th }}$ Mar 2020; accepted 29 $9^{\text {th }}$ Jul 2020)

\begin{abstract}
A meta-analysis was conducted to investigate the effect of returning farmlands to forests or pastures on soil animal diversity and its regional differentiation characteristics in China. Overall, based on the Shannon-Wiener index and Simpson index values, we found that returning farmland to forest (pasture) had an important effect on soil animal diversity. Forests and pastures might have a higher species richness and lower species evenness of soil animals than farmland. The effect of returning farmland to forest on soil animal diversity was greater than the effect of a return to pasture, although the effects varied between different land use/cover changes. The Shannon-Wiener index and Simpson index values showed different regional characteristics of soil animals when returning farmland to forest (pasture) in North China, South China, Northwest China and Qinghai-Tibet China. Returning farmland to forest (pasture) should be more conducive to increasing soil animal species richness in high-temperature regions and increasing soil animal species evenness in low-temperature regions. Furthermore, in low-temperature regions, returning farmland to forest affected the soil animal diversity more than returning farmland to pasture. Returning farmland to forest was more conducive in improving soil animal diversity synthetically in dry regions, and the changes in soil animal diversity due to the effect of returning farmland to pasture were not evident between dry and rainy regions in China.
\end{abstract}

Keywords: soil fauna, Shannon-Wiener index, Simpson index, land use, land cover, species richness, species evenness, meta-analysis

\section{Introduction}

Currently, with global attention focused on biodiversity and its protection, soil animal diversity and its ecological service functions have attracted widespread international and local attention from scholars (Bardgett and Cook, 1998; Shao et al., 2015). Soil animals are an integral component of soil ecosystems and play the role of consumers and decomposers in ecosystems (Albers et al., 2006). These animals have important effects on soil formation, soil structure, fertility conservation and energy flow (Bardgett and Wardle, 2010). Environmental changes and external disturbances could affect the composition and distribution of the soil animal community (Ponge et al., 2013; Baretta et al., 2014).

Land use/cover changes affect the input of litter, leading to changes in soil physicochemical properties, and change the characteristics of the soil animal 
community (Jangid et al., 2011; Liu et al., 2011). Many related studies have shown that vegetation type, soil organic matter, and soil physicochemical properties have important effects on soil animal community structure. For example, changes in land use patterns from forest to farmland radically change vegetation types, resulting in changes in a number of environmental factors, such as soil organic matter, soil temperature and water, and thus changing the structure and composition of the soil animal community (Tan et al., 2008; Yin et al., 2010). Some researchers suggested the richness and diversity of soil animals were influenced by a wide range of agricultural and other land use practices (Baker, 1998), and land-use intensification strongly influenced biodiversity by altering habitat heterogeneity, the distribution of habitat types and their expanse (Eggleton et al., 2005). The richness of different soil animal groups showed contrasting relationships with location and land-use type (Birkhofer et al., 2012).

Returning farmland to forest (pasture) is a China's governmental environmental program that converts arable land to forestry plantation or permanent pasture in order to protect and improve the ecological environment with the principle of sustainable development. Returning farmland to forest (pasture) is a major ecological restoration policy for controlling soil erosion and desertification in China. The process prevents soil erosion by ending land cultivation operations, planting trees and grass, restoring vegetation and controlling soil erosion ( $\mathrm{Li}$ et al., 2008). The implementation of this policy can cause large-scale and transformative changes in surface cover, but due to the difference of surface vegetation between forest and pasture, the distribution of litter and underground organic matter shows obvious differences, which has a significant different effect on the regional ecological environment, and subsequently affects differently the habitat conditions and diversity of soil animals (Yang, 2004; Liu and Men, 2009). Land use changes across China demonstrated significantly temporal and spatial differences during the last two decades (1990-2010). The area of farmland decreased in the South China and increased in North China. Forest decreased first, and then increased. Pasture continued decreasing (Sun et al., 2018). Thus, increasing interests focused on the effect of land use changes on soil animal diversity in China. Chinese scholars have conducted a series of studies on the changes in soil animal diversity under different land use/cover changes, such as changes between farmland, forest and pasture (Liu et al., 2011; Zhang et al., 2014; Wei et al., 2014). However, due to the complexity of the underground soil ecosystem, previous studies have failed to draw comprehensive conclusions regarding the effect of land use/cover changes on soil animal diversity or to clarify soil animal diversity after the implementation of the policy of returning farmland to forest (pasture) in China. Therefore, correctly and scientifically evaluating the effect of land use/cover change on soil animal diversity has great significance for the scientific management of land, the protection of soil animal diversity and the maintenance of soil ecological function. In addition, China's four geographic regions are North China, South China, Northwest China and Qinghai-Tibet China. The regional characteristics are significant, which include topography, climate and vegetation types, etc. The above factors have important effects on soil animal diversity. So here, regional differentiation characteristics of the effect on soil animal diversity under the policy of returning farmland to forest (pasture) in China is investigated. A meta-analysis is a comprehensive statistical analysis of different studies based on the same research topic (Sun et al., 2015). Meta-analyses have been applied in ecological studies in China (Tian et al., 2014; Zhang et al., 2015; Zhao et al., 2017). 
However, there have been no reports of meta-analyses on the effect of returning farmland to forest (pasture) on soil animal diversity. Based on a meta-analysis, the effect and regional differentiation characteristics of land use/cover change on soil animal diversity caused by the policy of returning farmland to forest (pasture) in China were comprehensively analysed.

\section{Materials and methods}

\section{Data collection and selection criteria}

We collected data on the effect of returning farmland to forest (pasture) on soil animal diversity in Chinese farmland from peer-reviewed articles published in both Chinese and English language journals from 1999 to 2018. The keywords used for the search included the following: returning farmland to forest, returning farmland to pasture, land use, land cover, vegetation types, soil animal, soil fauna, diversity, farmland, forest, and pasture. The articles in Chinese were collected from the China National Knowledge Infrastructure (CNKI) database, and those in English were from ISI-Web of Science and Google Scholar. Articles were only included if they met the following criteria: 1) the study area needed a detailed geographical location; 2) there was at least one land use change that included returning farmland to forest, returning farmland to pasture or converting forest to pasture; 3) there was at least one detailed chart or description of the soil animal diversity index (Shannon-Wiener or Simpson) before and after the land use change; 4) the soil animal sampling methods, determination methods, and diversity analysis and calculation methods were identical; 5) the means and sample sizes had to be reported; and 6) returning farmland to forest (pasture) could be represented by two different land use types as long as they were located in adjacent sites. The process was conducted following the flowchart diagram presented in Fig. 1 (Moher et al., 2009), and a total of 60 peer-reviewed articles were selected for our analysis (Appendix). Then in those 60 articles, the data of soil animal group number and density was collected for meta-analysis to investigate the change before and after land use change.

\section{Data grouping}

To investigate the regional differentiation characteristics of the effect of returning farmland to forest (pasture) on soil animal diversity, the selected data were grouped. For China, according to the comprehensive characteristics of geographical location, physical geography and human geography, the data were divided into four groups: North China, South China, Northwest China and Qinghai-Tibet China, which the boundary between North China and South China is Qinling and Huaihe, the boundary between North China and Northwest China is the Greater Khingan Mountains and the Great Wall, and the boundary between Northwest China and Qinghai-Tibet China is Kunlun Mountains and Qilian Mountains (Chi et al., 2015). In order to further investigate the regional differentiation characteristics, we divided the regions according to annual average temperature $\left(<12^{\circ} \mathrm{C}\right.$ and $\left.>12^{\circ} \mathrm{C}\right)$ and annual rainfall $(<200 \mathrm{~mm}, 200-400 \mathrm{~mm}$, $400-800 \mathrm{~mm}$ and $>800 \mathrm{~mm}$ ) because of the annual average temperature of study regions and the division base of semi-arid, semi-humid and humid region in China. 


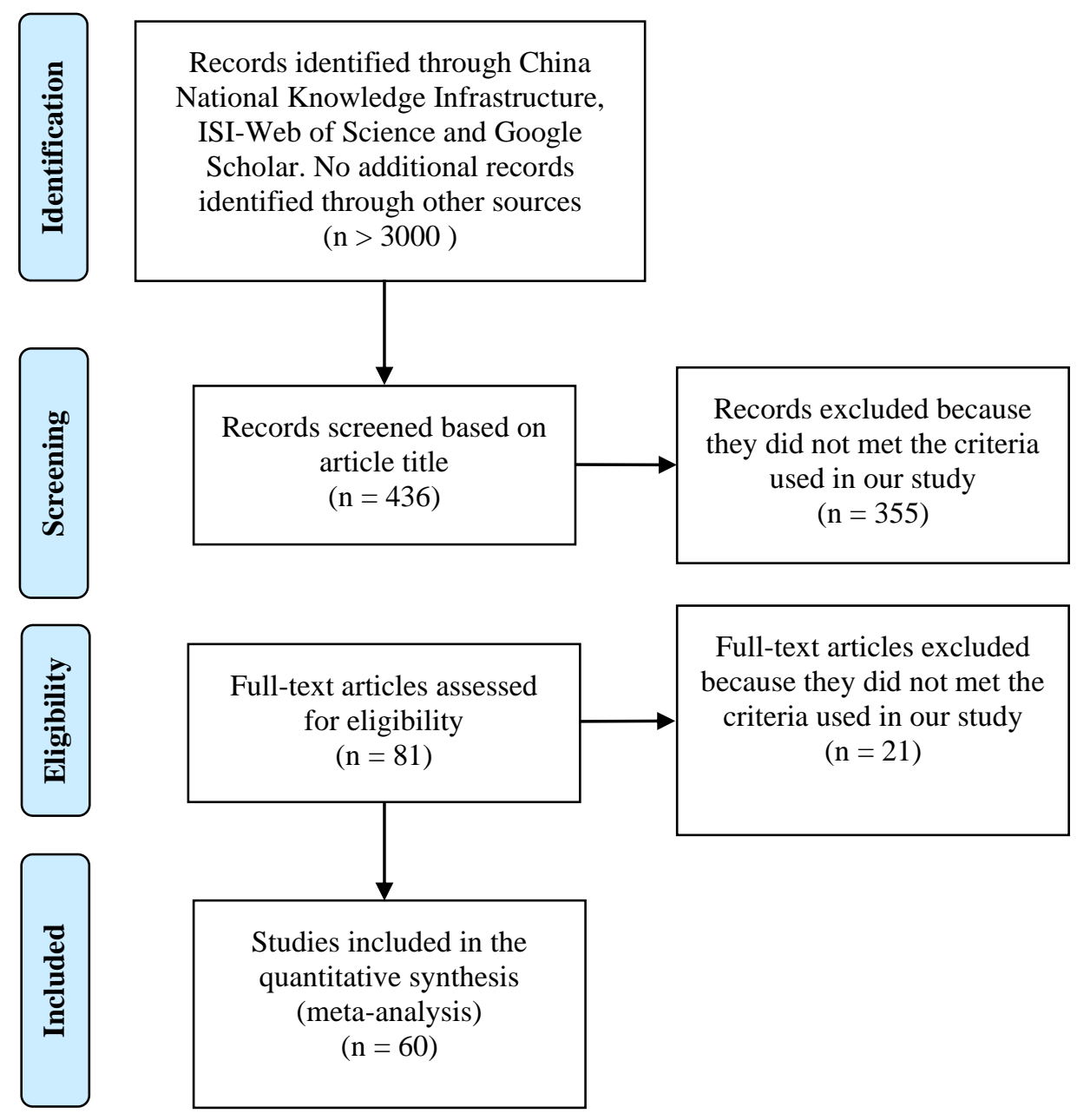

Figure 1. Flowchart diagram of the process used to obtain the literature data to build the database in our study

\section{Data analysis}

The Shannon index (Shannon, 1948) and Simpson index (Simpson, 1949) were selected as our soil animal diversity metrics because they are often used for analyzing soil animal alpha diversity in soil ecology (Bardgett and Cook, 1998; Wang et al., 2018). Although the Shannon index and Simpson index consider both species richness and species evenness, the Simpson index is more sensitive to community species evenness (Magurran, 1988; Xu et al., 2011). A large Simpson index value indicates that soil animals are unevenly distributed and the ecological functions of dominant species are prominent. The simultaneous increase in the Shannon index and decrease in the Simpson index indicate an increase in soil animal diversity. However, it is possible that the Shannon index and Simpson index increase simultaneously under the same treatment, which generally indicates potential species evenness loss. The Shannon index and Simpson index are calculated using the following equations:

$$
\text { Shannon index }=-\sum_{i=1}^{S} p_{i} \ln p_{i}
$$




$$
\text { Simpson index }=\sum_{i=1}^{S} p_{i}^{2}
$$

where $p_{i}$ is the proportion of individuals of category " $i$ " to the total number of individuals in the community and $S$ is the number of groups.

The variance in each index and the sample sizes of the corresponding research were included in our study. Web Plot Digitize software 3.12 (Rohatgi, 2012) was used to extract the data from the articles that provided only graphics. The variances were obtained by contacting the authors of the articles when the variance data were missing. If the variance data could not be obtained in some articles, the proportion of the variance to the average value of the existing data was used as the standard for calculating the variance based on previous studies (Skinner et al., 2014).

In ecological studies, the meta-analysis effect size was generally shown by the natural logarithm of the response ratio $(\mathrm{R})$, and the objective regulations reflected in selected research data were obtained by using weighted integral method (Hedges, 1999). In this study, the ratio of the average index $\left(X_{t}, X_{c}\right)$ of soil animal diversity before and after returning farmland to forest (pasture) was taken as the response ratio, and the natural $\log$ arithm $(\ln R)$ was taken as the effect size.

$$
\ln R=\ln \frac{X_{t}}{X_{c}}=\ln X_{t}-\ln X_{c}
$$

where $R$ is the response ratio, $\ln R$ is the effect size, $X_{t}$ is the mean value of each index before returning farmland to forest (pasture) and $X_{c}$ is the mean value of each index after returning farmland to forest (pasture). The effect size of each data pair was obtained by meta-analysis, and the weighted mean effect size, $\ln R_{++}$, and its $95 \%$ confidence intervals were obtained by calculating the weight based on the standard deviation.

The effect of returning farmland to forest (pasture) on soil animal diversity was significant $(P<0.05)$ if all confidence intervals were greater than 0 . Conversely, there was a significant negative effect $(P<0.05)$ if the confidence intervals were all less than 0 . If 0 was within the confidence interval, returning farmland to forest (pasture) had a nonsignificant effect on soil animal diversity. We also used the percentage transformed from the mean effect size to explain the response of soil animal diversity on returning farmland to forest (pasture):

$$
\left(e^{\left.\ln R_{++}-1\right)} \times 100 \%=\left(R_{++}-1\right) \times 100 \%\right.
$$

Publication bias was quantified by rank-correlation methods, which included Kendall's tau and Spearman's rank-order method; a $P<0.05$ indicates the existence of publication bias (Begg and Mazumdar, 1994). Rosenthal's fail-safe method (Rosenthal, 1979) was used to evaluate the publication bias results (Table 1). When the fail-safe number is considerably larger than $5 k+10$ (where $k$ is the original number of studies), the result is not affected by publication bias and the meta-analysis result is reliable (Hoeve et al., 2012). In this study, Metawin 2.1 software (Rosenberg et al., 2000) was used for the meta-analysis, and Origin 8.5 software was used for generating the figures. 
Table 1. Results of publication bias were tested and evaluated. FLF represents returning farmland to forest; FLP represents returning farmland to pasture; and FP represents the conversion from forest to pasture

\begin{tabular}{|c|c|c|c|c|}
\hline \multirow{2}{*}{\multicolumn{2}{|c|}{ Categories }} & $\begin{array}{c}\text { Kendall's Tau } \\
\text { method }\end{array}$ & $\begin{array}{c}\text { Spearman's rank-order } \\
\text { method }\end{array}$ & $\begin{array}{c}\text { The Rosenthal's fail-safe } \\
\text { method }\end{array}$ \\
\hline & & P-value & P-value & Fail-safe number \\
\hline $\begin{array}{l}\text { Shannon } \\
\text { index }\end{array}$ & $\begin{array}{l}\text { FLF } \\
\text { FLP } \\
\text { FP } \\
\end{array}$ & $\begin{array}{l}0.7266 \\
0.5912 \\
0.4925 \\
\end{array}$ & $\begin{array}{l}0.6821 \\
0.5492 \\
0.5999 \\
\end{array}$ & $\begin{array}{l} \\
- \\
- \\
\end{array}$ \\
\hline $\begin{array}{l}\text { Simpson } \\
\text { index }\end{array}$ & $\begin{array}{l}\text { FLF } \\
\text { FLP } \\
\text { FP } \\
\end{array}$ & $\begin{array}{l}0.3484 \\
0.6833 \\
\mathbf{0 . 0 0 5 8} \\
\end{array}$ & $\begin{array}{l}0.4561 \\
0.6332 \\
\mathbf{0 . 0 0 9 6} \\
\end{array}$ & $\begin{array}{c}- \\
- \\
1449>5 k+10 \\
\end{array}$ \\
\hline
\end{tabular}

\section{Results}

\section{Effect of returning farmland to forest (pasture) on soil animal diversity}

Across all studies, the Shannon-Wiener index and Simpson index showed different responses by soil animals to returning farmland to forest (pasture) (Fig. 2). The Shannon-Wiener index results showing the effect of returning farmland to forest (pasture) on soil animals are shown in Fig. 2a. On average, the Shannon-Wiener index value for forest was $18.35 \%$ higher than that of farmland, which was significant; however, compared with farmland, the mean effect size of the Shannon-Wiener index value for pasture was positive, but the effect was nonsignificant. In addition, the Shannon-Wiener index value significantly decreased by $9.71 \%$ from forest to pasture. The effect of returning farmland to forest (pasture) on soil animals by the Simpson index is shown in Fig. 2b. According to Fig. 2b, the Simpson index changed significantly with the conversion of land use types, which was caused by returning farmland to forest (pasture). On average, the Simpson index significantly increased by $2.14 \%$ and $3.38 \%$ in changing farmland to forest and pasture, respectively. In addition, the Simpson index value for forest was $4.32 \%$ lower than that of pasture. According to Fig. 3, the group number and density of soil animals significantly increased by $9.31 \%$ and $46.69 \%, 3.86 \%$ and $62.24 \%$ when returning farmland to forest and pasture, respectively.

\section{Regional differentiation characteristics of the effect of returning farmland to forest (pasture) on soil animal diversity}

The Shannon-Wiener index and Simpson index values showed different regional characteristics of returning farmland to forest (pasture) on soil animals in China (Fig. 4). According to Fig. 4a, in North and South China, the Shannon-Wiener index value for forest was $34.21 \%$ and $17.75 \%$ higher than that of farmland, respectively, which was significant. However, compared with farmland, the mean effect size of the Shannon-Wiener index value for forest was negative, and the effect was nonsignificant in Northwest China. The Simpson index value significantly increased by $5.68 \%$ and $3.37 \%$ when returning farmland to forest in North and South China, respectively, but significantly decreased by $10.64 \%$ in Northwest China. According to Fig. $4 b$, in North and Qinghai-Tibet China, the Shannon-Wiener index value for pasture was $50.92 \%$ and $25.59 \%$ higher than that for farmland, respectively. In Northwest China, the Shannon-Wiener index value for pasture significantly decreased by $21.05 \%$, and the effect was nonsignificant despite the negative mean effect size in South China. When 
returning farmland to pasture, the Simpson index value significantly decreased by 9.36\% and 9.62\% in North and South China, respectively. In Qinghai-Tibet China, the Simpson index value for pasture significantly increased by $63.57 \%$, and the mean effect size was positive. However, the effect was nonsignificant in Northwest China. According to Fig. 4c, in the conversion from forest to pasture, the mean effect size of the Shannon-Wiener index was negative, and the effects were nonsignificant in North and South China. The Shannon-Wiener index value for pasture was $14.52 \%$ lower than that for forest in Northwest China. The Simpson index value for pasture significantly decreased by $1.93 \%$ in South China and significantly increased by $23.06 \%$ in Northwest China. In addition, the effect was nonsignificant in North China.

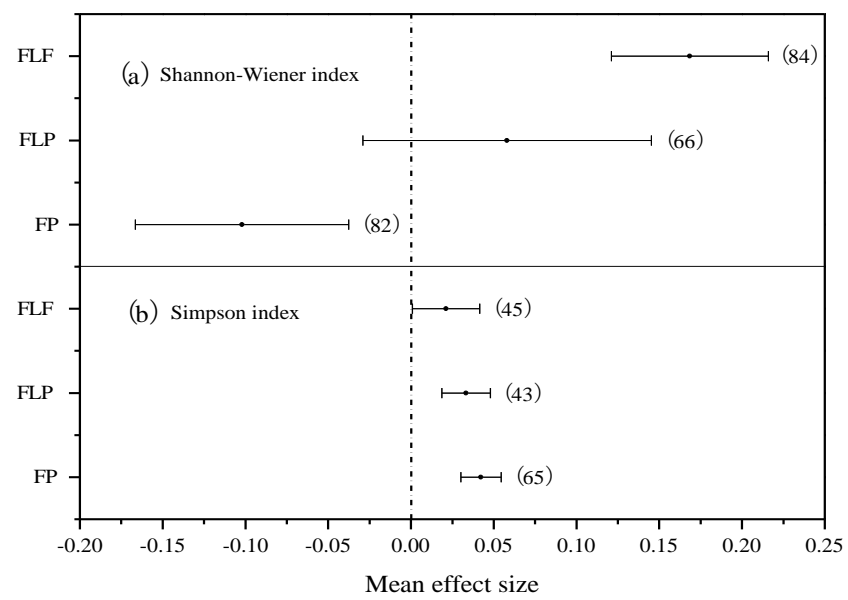

Figure 2. Effect of returning farmland to forest (pasture) on the Shannon index (a) and Simpson index (b) values. The error bars represent $95 \%$ confidence intervals (CIs). The solid circle represents the mean effect size. The numbers represent the number of observations, and the dashed line is a mean effect size of 0 . FLF represents returning farmland to forest; FLP represents returning farmland to pasture; and FP represents the conversion from forest to pasture
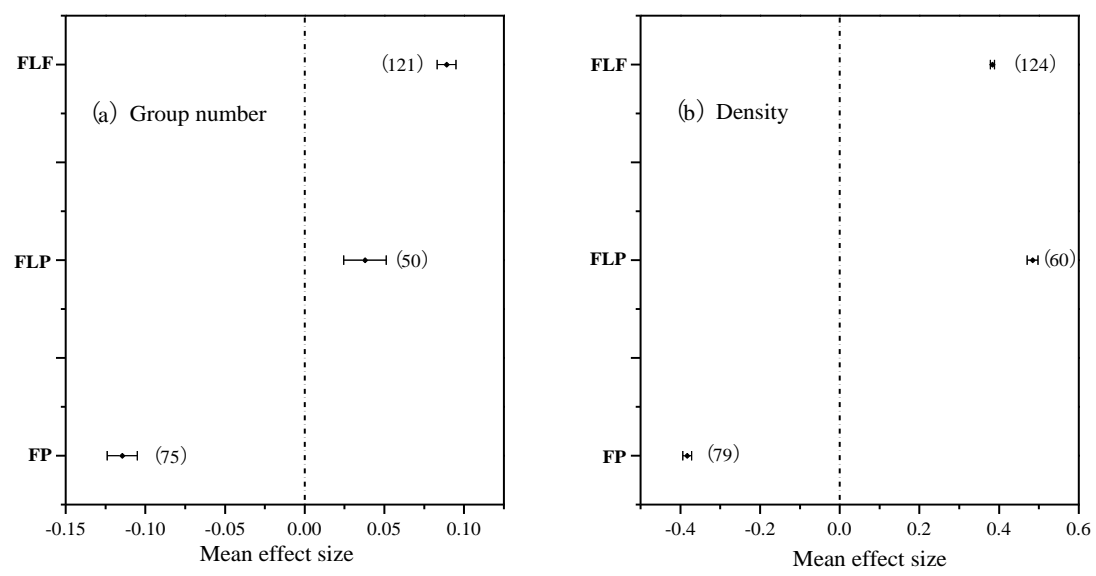

Figure 3. Effect of returning farmland to forest (pasture) on the group number (a) and density (b). The error bars represent $95 \%$ confidence intervals (CIs). The solid diamonds represent the mean effect size. The numbers represent the number of observations, and the dashed line is a mean effect size of 0 . FLF represents returning farmland to forest; FLP represents returning farmland to pasture; and FP represents the conversion from forest to pasture 


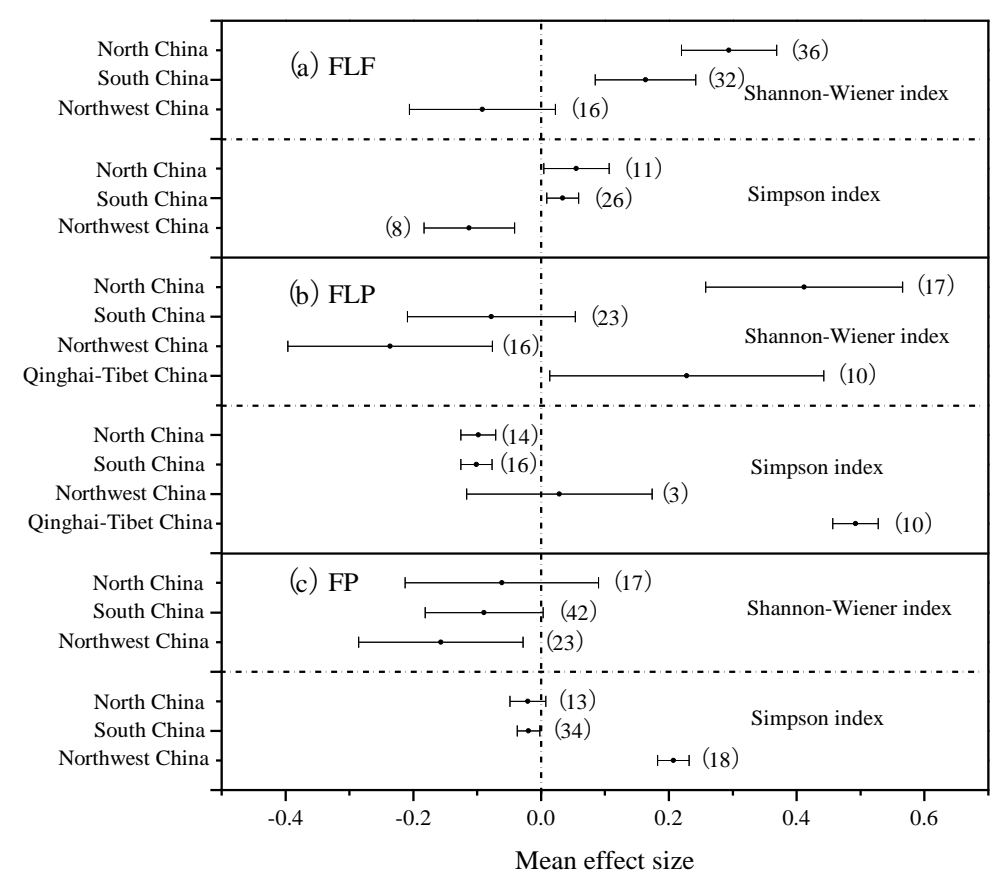

Figure 4. Regional characteristics of the effect on the Shannon index and Simpson index values of FLF (a), FLP (b) and FP (c). The error bars represent 95\% confidence intervals (CIs). The solid circle represents the mean effect size. The numbers represent the number of observations, and the dashed line is a mean effect size of 0. FLF represents returning farmland to forest; FLP represents returning farmland to pasture; and FP represents the conversion of forest to pasture

According to Fig. 5, in North China, returning farmland to forest had significant positive effects on the group number and density of soil animals, $29.62 \%$ and $124.13 \%$, respectively. Moreover, returning farmland to pasture had significant positive effects on group number and density, with percentages of $65.68 \%$ and $164.86 \%$, respectively. In South China, returning farmland to forest had significant positive effects on the group number and density of soil animals, with percentages of $23.59 \%$ and $56.85 \%$, respectively. Moreover, the group number of pastures was $10.97 \%$ higher than that of farmland, which was significant. However, the effect of density was nonsignificant compared with the effect of farmland. In Northwest China, returning farmland to forest decreased the group number and density significantly by $13.84 \%$ and $11.44 \%$, respectively, and returning farmland to pasture changed the percentages of the group number and density were $-11.88 \%$ and $16.78 \%$, respectively. In Qinghai-Tibet China, returning farmland to pasture changed the percentages of the group number and density were $7.88 \%$ and $84.81 \%$, respectively.

\section{Regional differentiation characteristics caused by temperature and rainfall}

When the average temperature was $<12^{\circ} \mathrm{C}$ and $>12^{\circ} \mathrm{C}$, returning farmland to forest significantly increased the Shannon index value by $18.60 \%$ and $17.72 \%$, respectively (Fig. 6a). Moreover, the Simpson index value significantly decreased by $10.13 \%$ when the average temperature was $<12^{\circ} \mathrm{C}$, and then significantly increased by $41.30 \%$ (Fig. $6 d$ ). In addition, the group number and density changed by $-3.79 \%$ and $11.28 \%$ when the average temperature was $<12^{\circ} \mathrm{C}$, and increased by $26.23 \%$ and $56.87 \%$ when the average temperature was $>12^{\circ} \mathrm{C}$ ( Fig. $7 a$ and $7 d$ ). Returning farmland to pasture 
significantly increased the Shannon index value by $12.73 \%$ and significantly decreased the Simpson index by $7.50 \%$ when the average temperature was $<12^{\circ} \mathrm{C}$. Moreover, the return significantly increased the Simpson index by $31.48 \%$ and had a nonsignificant effect on the Shannon index when the average temperature was $>12^{\circ} \mathrm{C}$ (Fig. $6 b$ and $6 e$ ). In addition, the group number and density changed by $-9.49 \%$ and $43.21 \%$ when the average temperature was $<12^{\circ} \mathrm{C}$, and they increased by $19.50 \%$ and $91.08 \%$ when the average temperature was $>12^{\circ} \mathrm{C}($ Fig. $7 b$ and $7 e)$.
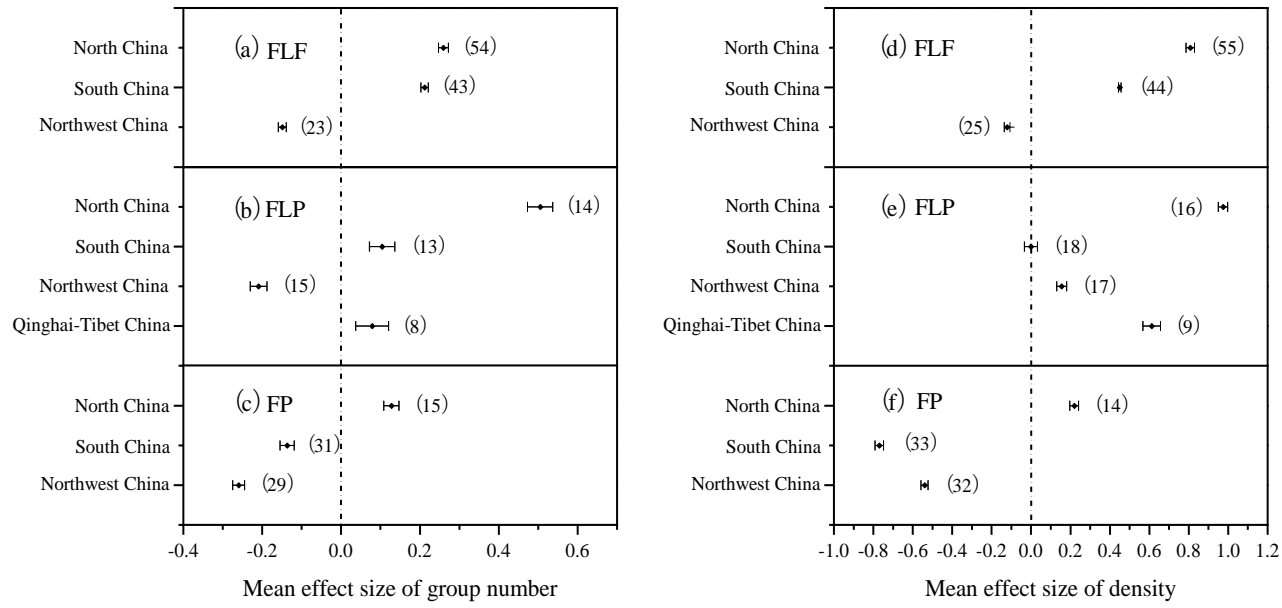

Figure 5. Regional characteristics of the effect on the group number of FLF $(a), F L P(b)$ and $F P(c)$ and density of $F L F(d), F L P(e)$ and $F P(f)$. The error bars represent $95 \%$ confidence intervals (CIs). The solid diamonds represent the mean effect size. The numbers represent the number of observations, and the dashed line is a mean effect size of 0 . FLF represents returning farmland to forest; FLP represents returning farmland to pasture; and FP represents the conversion from forest to pasture
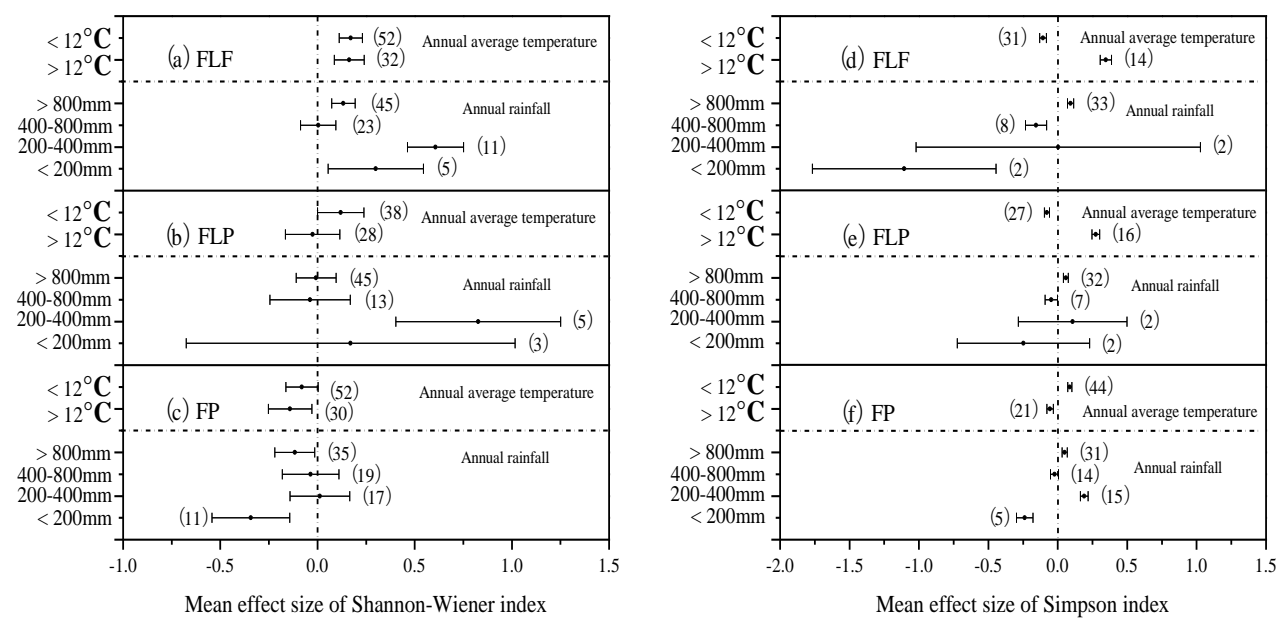

Figure 6. Effect of returning farmland to forest (pasture) on the Shannon index values of FLF

$(a), F L P(b)$ and $F P(c)$ and the Simpson index values of FLF (d), FLP (e) and FP (f) with changes in temperature and rainfall. The error bars represent $95 \%$ confidence intervals (CIs).

The solid circle represents the mean effect size. The numbers represent the number of observations, and the dashed line is a mean effect size of 0 . FLF represents returning farmland to forest; FLP represents returning farmland to pasture; and FP represents the conversion from forest to pasture 

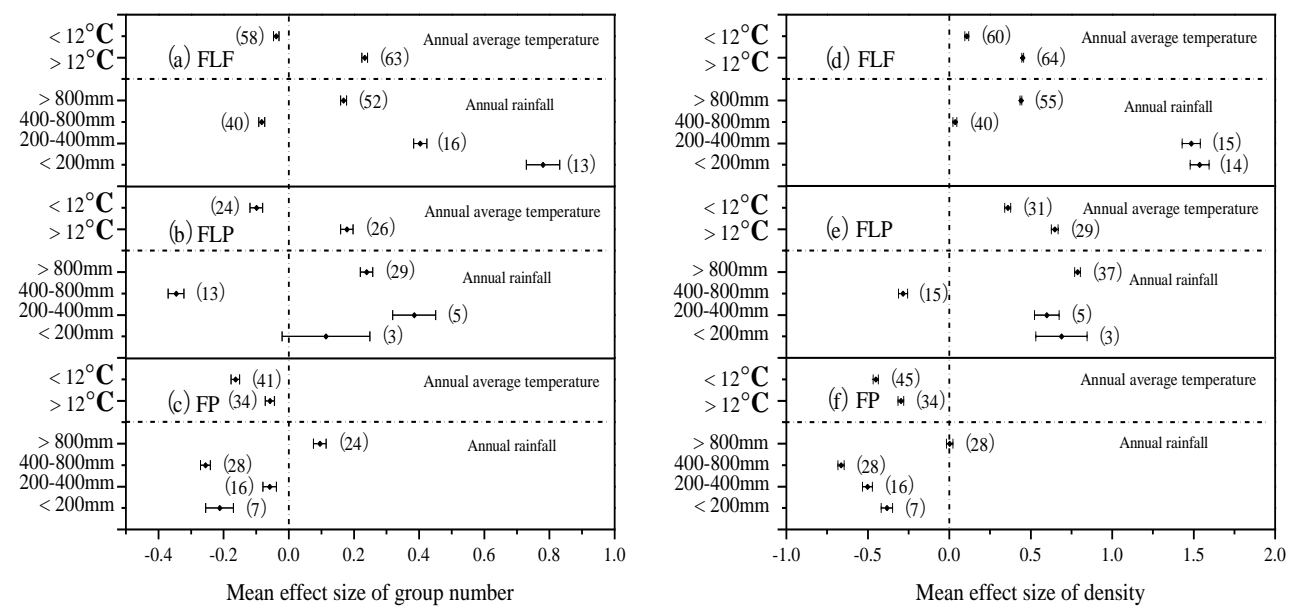

Figure 7. Regional characteristics of the effect on the group number of FLF $(a), F L P(b)$ and $F P(c)$ and density of $F L F(d), F L P(e)$ and $F P(f)$ with the temperature and rainfall changes.

The error bars represent $95 \%$ confidence intervals (CIs). The solid diamonds represent the mean effect size. The numbers represent the number of observations, and the dashed line is a mean effect size of 0 . FLF represents returning farmland to forest; FLP represents returning farmland to pasture; and FP represents the conversion from forest to pasture

With an increase in annual rainfall, returning farmland to forest significantly increased the Shannon index by $34.94 \%, 83.5 \%$, and $14.24 \%$, except for the nonsignificant effect at 400-800 mm (Fig. 6a). The Simpson index significantly decreased by $66.91 \%$ and $14.45 \%$, at amounts $<200 \mathrm{~mm}$ and $400-800 \mathrm{~mm}$ and then increased significantly by $9.67 \%$ at amounts $>800 \mathrm{~mm}$, but there was a nonsignificant effect at amounts from 200-400 mm (Fig. 6d). In addition, the group number changed by $118.17 \%, 49.68 \%,-7.98 \%$ and $18.3 \%$, and the density changed by $364.80 \%$, $341.57 \%, 3.51 \%$ and $55.22 \%$ when the amount was $<200 \mathrm{~mm}$ to $>800 \mathrm{~mm}$ (Fig. $7 a$ and $7 d$ ). Returning farmland to pasture significantly increased the Shannon index by $128.71 \%$ at amounts from $200-400 \mathrm{~mm}$ but had a nonsignificant effect in other regions (Fig. 6b). The Simpson index decreased significantly by $4.59 \%$ at amounts between 400-800 $\mathrm{mm}$ and then increased significantly at amounts $>800 \mathrm{~mm}$, but there was a nonsignificant effect in other regions (Fig. 6e). In addition, the group number changed by $46.89 \%,-29.25 \%$ and $26.92 \%$ at amounts from $200-400 \mathrm{~mm}$ to $>800 \mathrm{~mm}$, and the density changed by $98.97 \%, 81.92 \%,-24.72 \%$ and $119.71 \%$ at amounts from $<200 \mathrm{~mm}$ to $>800 \mathrm{~mm}$. Returning farmland to pasture had a nonsignificant effect on the group number at amounts $<200 \mathrm{~mm}$ (Fig. $7 b$ and $7 e$ ).

\section{Discussions}

\section{Returning farmland to forest}

Under China's governmental environmental program of returning farmland to forest, a large amount of farmland has been converted to forest (Wang et al., 2011). The conversion of land use types has changed the cycling of soil organic matter (Detwiler, 1986; Zhao et al., 2014), the soil physicochemical properties (Adejuwon and Ekanade, 1988; Toohey et al., 2018) and the soil animal habitat (Eggleton et al., 2005). As a result, there have been important effects on soil animal diversity. The results of the 
present study confirm that returning farmland to forest has an important effect on soil animal diversity, as indicated by the Shannon-Wiener index and Simpson index values, and indicate that returning farmland to forest increases soil animal richness. However, returning farmland to forest might have decreased the soil animal evenness and increased the proportion of dominant species. This result was consistent with previous studies regarding the effects of changes from farmland to forest on soil animal diversity. Bartz et al. (2014) found that forest provided better soil conditions for the development of a higher diversity of soil animal compared to farmland. Okwakol (2010) also reported that forest had a higher soil animal diversity compared with farmland.

\section{Returning farmland to pasture}

Returning farmland to pasture had an important effect on soil animal diversity, but its effect on the Shannon index and Simpson index values were inconsistent (Fig. 2). The Simpson index value significantly increased by $3.38 \%$, which indicated that soil animal evenness decreased and the proportion of dominant species increased. The above results show that the nonsignificant effect on the Shannon index might have been caused by the comprehensive results of an increase in species richness and a decrease in species evenness, which was suggested by the results of our study (Fig. 2). Similar results were reported by Cluzeau et al. (2012), who demonstrated most of the soil animal groups exhibited lower values of abundance and community richness in farmland than in pasture. In addition, regarding the conversion from forest to pasture, the Shannon index value decreased and the Simpson index value increased, indicating a decrease in soil animal diversity $(-9.71 \%, 4.32 \%)$. This was consistent with the results obtained by Callaham et al. (2006). The group number and density of soil animals significantly decreased, which might have been caused by the lower soil animal richness and soil animal evenness of pastures compared with forests because the distribution patterns of the soil animal community changed with the change in surface vegetation cover (Vohland and Schroth, 1999; Yin et al., 2017).

\section{Regional differentiation characteristics}

There were significant differences in topography, climate, soil properties and vegetation types in North China, South China, Northwest China and Qinghai-Tibet China, which had important effects on soil animal diversity. So the effect on soil animal diversity showed different regional characteristics when returning farmland to forest (pasture). In North China, returning farmland to forest increases soil animal species richness, and soil animal species evenness might decrease. While returning farmland to pasture increased both the species richness and species evenness of soil animals, returning farmland to pasture significantly increased the soil animal diversity. The effect on soil animal diversity was nonsignificant because the changes in the Shannon index and Simpson index values were nonsignificant in the change from forest to pasture even though the species richness increased. In South China, returning farmland to forest has an important effect on soil animal diversity, which might have been caused by the increase in species richness and the decrease in species evenness of soil animals. Returning farmland to pasture increased soil animal diversity, which might be caused by the highly significant increases in species richness and species evenness even though the effect indicated by the Shannon index was nonsignificant. In addition, the changes in soil animal diversity might have been caused by both a decrease in species richness and an increase in species evenness from the conversion of forest to pasture. In 
Northwest China, the increase in soil animal diversity might have been caused mainly by the increase in species evenness when returning farmland to forest. Returning farmland to pasture can decrease soil animal diversity largely due to a decrease in species richness. With the conversion from forest to pasture, the change percentages of the group number and density were $-12.77 \%$ and $-41.75 \%$, respectively (Fig. 5). The Shannon index value decreased significantly, and the Simpson index increased significantly, which might have been caused by the significant decrease in species richness and species evenness. In Qinghai-Tibet China, returning farmland to pasture has an effect on soil animal diversity, which was possibly caused by the increase in species richness and decrease in species evenness. The above regional differentiation characteristics were supported by some studies of land use change affecting soil animal diversity in other countries and regions, which indicated that the effect of land use change on soil animal diversity showed different regional differences with the change of geographical environment (Rossi and Blanchart, 2005; Karanja et al., 2009; Begum et al., 2013; Steinwandter et al., 2017).

\section{Effect of temperature and rainfall}

In China, the effect on soil animal diversity showed different regional characteristics when returning farmland to forest (pasture) because of differing regional natural conditions. The regional climate conditions mainly include temperature and rainfall, which have important effects on the cycling of soil organic matter and soil physicochemical properties (Kirschbaum, 1995; Mani et al., 2018). Therefore, to further discuss the regional differentiation characteristics, we divided the regions according to the annual average temperature and annual rainfall in China.

Returning farmland to forest (pasture) should be more conducive to increasing soil animal species richness in high-temperature regions and increasing soil animal species evenness in low-temperature regions. The improvement of plant community coverage and vegetation height after converting farmland greatly improved the survival conditions of soil animals and attract more soil animals to inhabit the land and survive (Mathieu et al., 2004). Additionally, the conversion was very beneficial for the concentration of dominant species. This benefit was proved by our study results, i.e., the proportion of dominant species increased in high-temperature regions. Returning farmland to pasture had a nonsignificant effect on the Shannon index when the average temperature was $>12^{\circ} \mathrm{C}$, which might be caused by the comprehensive effect of both the increase in species richness and the decrease in species evenness. Furthermore, in low-temperature regions, returning farmland to forest affected soil animal diversity more than a return to pasture because the mean effect size of the Shannon index decreased and the Simpson index increased from forest to pasture when the annual average temperature was $<12^{\circ} \mathrm{C}$.

With an increase in annual rainfall, the effect of returning farmland to forest on species richness and evenness gradually decreased and was conducive to the concentration of dominant species. Our study found that arid regions were more conducive to improving soil animal diversity when returning farmland to forest because soil animals are more sensitive to vegetation changes under drought conditions (Schlaghamerský et al., 2014). Alternatively, the result might be because of the lower amount of data in the meta-analysis. While the regional differentiation characteristics of the effect of returning farmland to pasture on soil animal diversity were not evident with the increase in annual rainfall, returning farmland to forest can increase soil animal 
diversity better the conversion to than pasture at amounts $<200 \mathrm{~mm}$. The Simpson index value increased significantly at amounts of $200-400 \mathrm{~mm}$, which could be interpreted by the increase in dominant species. At amounts $>800 \mathrm{~mm}$, the Shannon index value decreased, which can be interpreted by the complicated comprehensive effect of both the increase in species richness and the decrease in species evenness. In particular, at amounts of 400-800 mm, returning farmland to forest (pasture) decreased the species richness but improved the species evenness. The specific reasons require further study.

\section{Conclusions}

Based on the results of our meta-analysis, the effects of returning farmland to forest (pasture) on soil animal diversity and its regional differentiation characteristics are complicated. The conclusions are as follows: (1) Overall, returning farmland to forest (pasture) had an important effect on soil animal diversity, which included the increase in species richness and the decrease in species evenness, and forests had a higher soil animal diversity than pastures; (2) In China, the effect of soil animal diversity showed different regional characteristics that largely depended on the specific geographic region and climate conditions, mainly temperature and rainfall, when returning farmland to forest (pasture).

In our study, a meta-analysis was used to investigate the effect of returning farmland to forest (pasture) on soil animal diversity, but in an actual underground ecosystem, many factors have different and comprehensive effects on soil animal diversity. Therefore, the analysis of regional differentiation characteristics and mechanisms requires further study. In addition, the reliability of some results may be reduced because effective data could not be obtained or the amount of data was relatively small, and therefore, future studies of these topics require further improvement.

Acknowledgments. We thank the library of the Northeast Institute of Geography and Agroecology of the Chinese Academy of Sciences for their support. We thank Michael S. Rosenberg for his help supplying the meta-analysis software. The present study was supported by the National Basic Research Program of China (No. 41430857).

\section{REFERENCES}

[1] Adejuwon, J. O., Ekanade, O. (1988): A comparison of soil properties under different land use types in a part of the Nigerian cocoa belt. - Catena 15(3-4): 319-331.

[2] Albers, D., Schaefer, M., Scheu, S. (2006): Incorporation of plant carbon into the soil animal food web of an arable system. - Ecology 87(1): 235-245.

[3] Baker, G. (1998): Recognising and responding to the influences of agriculture and other land-use practices on soil fauna in Australia. - Applied Soil Ecology 9(1): 303-310.

[4] Bardgett, R. D., Cook, R. (1998): Functional aspects of soil animal diversity in agricultural grasslands. - Applied Soil Ecology 10(3): 263-276.

[5] Bardgett, R. D., Wardle, D. A. (2010): Aboveground-belowground linkages: biotic interactions, ecosystem processes, and global change. - Oxford: Oxford University Press.

[6] Baretta, D., Bartz, M. L. C., Fachini, I., Anselmi, R., Zortéa, T., Duarte, C. R., Baretta, M. (2014): Soil fauna and its relation with environmental variables in soil management systems. - Revista Ciencia Agronomica 45(5): 871-879. 
[7] Bartz, M., Brown, G. G., Orso, R., Mafra, A. L., Baretta, D. (2014): The influence of land use systems on soil and surface litter fauna in the western region of Santa Catarina. Revista Ciencia Agronomica 45(5): 880-887.

[8] Begg, C. B., Mazumdar, M. (1994): Operating characteristics of a rank correlation test for publication bias. - Biometrics 50(4): 1088-1101.

[9] Begum, F., Bajracharya, R. M., Sitaula, B. K., Sharma, S. (2013): Seasonal dynamics, slope aspect and land use effects on soil mesofauna density in the mid-hills of Nepal. International Journal of Biodiversity Science, Ecosystem Services \& Management 9(4): 290-297.

[10] Birkhofer, K., Schöning, I., Alt, F., Herold, N., Klamer, B., Maraun, M., Marhan, S., Oelmann, Y., Wubet, T., Yurkov, A., Begerow, D., Berner, D., Buscot, F., Schrumpf, M. (2012): General relationships between abiotic soil properties and soil biota across spatial scales and different land-use types. - PLoS ONE 7(8): e43292.

[11] Callaham, M. A., Richter, D. D., Coleman, D. C., Hofmockel, M. (2006): Long-term land-use effects on soil invertebrate communities in Southern Piedmont soils, USA. European Journal of Soil Biology 42: S150-S156.

[12] Chi, X., Zhan, E. Y., Wang, X., Sun, Y. (2015): Spatiotemporal variations of precipitation extremes of china during the past 50 years (1960-2009). - Theoretical and Applied Climatology 124(3-4): 555-564.

[13] Cluzeau, D., Guernion, M., Chaussod, R., Martin-Laurent, F., Villenave, C., Cortet, J., Ruiz-Camacho, N., Pernin, C., Mateille, T., Philippot, L., Bellido, A., Rougé, L., Arrouays, D., Bispo, A., Péres, G. (2012): Integration of biodiversity in soil quality monitoring: Baselines for microbial and soil fauna parameters for different land-use types. - European Journal of Soil Biology 49: 63-72.

[14] Detwiler, R. P. (1986): Land use change and the global carbon cycle: the role of tropical soils. - Biogeochemistry 2(1): 67-93.

[15] Eggleton, P., Vanbergen, A. J., Jones, D. T., Lambert, M. C., Rockett, C., Hammond, P. M., Beccaloni, J., Marriott, D., Ross, E., Giusti, A. (2005): Assemblages of soil macrofauna across a Scottish land-use intensification gradient: influences of habitat quality, heterogeneity and area. - Journal of Applied Ecology 42(6): 1153-1164.

[16] Hedges, L. V., Gurevitch, J., Curtis, P. S. (1999): The meta analysis of response ratios in experimental ecology. - Ecology 80: 1150-1156.

[17] Hoeve, M., Stams, G. J. J. M., van der Put, C. E., Dubas, J. S., van der Laan, P. H., Gerris, J. R. M. (2012): A meta-analysis of attachment to parents and delinquency. - Journal of Abnormal Child Psychology 40(5): 771-785.

[18] Jangid, K., Williams, M. A., Franzluebbers, A. J., Schmidt, T. M., Coleman, D. C., Whitman, W. B. (2011): Land-use history has a stronger impact on soil microbial community composition than aboveground vegetation and soil properties. - Soil Biology \& Biochemistry 43(10): 2184-2193.

[19] Karanja, N., Ayuke, F., Muya, E., Kibberenge, M., Nyamasyo, G. (2009): Soil macrofauna community structure across land use systems of taita, kenya. - Tropical and Subtropical Agroecosystems 11(2): 385-396.

[20] Kirschbaum, M. U. F. (1995): The temperature dependence of soil organic matter decomposition, and the effect of global warming on soil organic $\mathrm{C}$ storage. - Soil Biology \& Biochemistry 27(27): 753-760.

[21] Li, D., Zhuo, J., Sun, Z. (2008): Monitoring the effects of ecosystem restructuring project after returning farmland to forest based on RS and GIS. - Transactions of the CSAE 24(12): 120-126.

[22] Liu, X. M., Men, L. N. (2009): Effects of grassland restoration from cropland on soil macrofaunal community in Wuchuan County, Inner Mongolia. - Chinese Journal of Ecology 20(8): 965-1972.

[23] Liu, Y., Zhang, A., Yan, Y. (2011): Diversity of soil animal community under different land-use types in Chongming island. - Journal of Fudan University 3: 288-295. 
[24] Liu, R., Zhao, X., Drake, S. (2011): Facilitative effects of shrubs in shifting sand on soil macro-faunal community in Horqin Sand Land of Inner Mongolia, Northern China. European Journal of Soil Biology 47(5): 316-321.

[25] Magurran, A. E. (1988): Ecological Diversity and Its Measurement. - Princeton University Pre.

[26] Mani, S., Merino, A., García-Oliva, F., Riotte, J. (2018): Soil properties and organic matter quality in relation to climate and vegetation in southern Indian tropical ecosystems. - Soil Research 56(1): 80-90.

[27] Mathieu, J., Rossi, J.-P., Grimaldi, M., Mora, P., Lavelle, P., Rouland, C. (2004): A multi-scale study of soil macrofauna biodiversity in Amazonian pastures. - Biology and Fertility of Soils 40(5): 300-305.

[28] Moher, D., Liberati, A., Tetzlaff, J., Altman, D. G. (2009): Preferred reporting items for systematic reviews and meta-analyses: the PRISMA statement. - Physical Therapy 89(9): 873-880.

[29] Okwakol, M. (2010): The effect of change in land use on soil macrofauna communities in Mabira Forest, Uganda. - African Journal of Ecology 32(4): 273-282.

[30] Ponge, J. F., Pérès, G., Guernion, M., Ruiz-Camacho, N., Cortet, J., Pernin, C., Villenave, C., Chaussod, R., Martin-Laurent, F., Bispo, A., Cluzeau, D. (2013): The impact of agricultural practices on soil biota: A regional study. - Soil Biology \& Biochemistry 67: 271-284.

[31] Rohatgi, A. (2012): Web Plot Digitalizer: HTML5 based online tool to extract numerical data from plot images. - Version 3.12. http://arohatgi.info/WebPlotDigitizer/citation.html.

[32] Rosenberg, M., Adams, D., Gurevitch, J. (2000): Meta win: statistical software for metaanalysis. - Version 2.1.

[33] Rosenthal, R. (1979): The file drawer problem and tolerance for null results. Psychological Bulletin 86(3): 638-641.

[34] Rossi, J., Blanchart, E. (2005): Seasonal and land-use induced variations of soil macrofauna composition in the Western Ghats, southern India. - Soil Biology \& Biochemistry 37(6): 1093-1104.

[35] Schlaghamerský, J., Devetter, M., Háněl, L., Tajovsky, K., Stary, J., Tuf, I. H., Pizl, V. (2014): Soil fauna across Central European sandstone ravines with temperature inversion: From cool and shady to dry and hot places. - Applied Soil Ecology 83: 30-38.

[36] Shannon, C. E. (1948): A mathematical theory of communication. - The Bell System Technical Journal 27(3): 379-423.

[37] Shao, Y. H., Zhang, W. X., Liu, S. J., Wang, X. L. (2015): Diversity and function of soil fauna. - Acta Ecologica Sinica 35(20): 6614-6625.

[38] Simpson, E. M. (1949): Measurement of diversity. - Nature 163: 688.

[39] Skinner, C., Gattinger, A., Muller, A. (2014): Greenhouse gas fluxes from agricultural soils under organic and non-organic management: A global meta-analysis. - Science of the Total Environment 468: 553-563.

[40] Steinwandter, M., Schlick-Steiner, B. C., Seeber, G. U. H., Steiner, F. M., Seeber, J. (2017): Effects of alpine land-use changes: soil macrofauna community revisited. Ecology and Evolution 7(14): 5389-5399.

[41] Sun, Y., Zeng, Y., Shi, Q., Pan, X., Huang, S. (2015): No-tillage controls on runoff: A meta-analysis. - Soil \& Tillage Research 153: 1-6.

[42] Sun, D., Yang, H., Guan, D., Yang, M., Wu, J., Yuan, F., Jin, C., Wang, A., Zhang, Y. (2018): The effects of land use change on soil infiltration capacity in China: A metaanalysis. - Science of the Total Environment 626: 1394-1401.

[43] Tan, Z., Pan, Z., An, P. (2008): Characteristics of soil water changes under different ways of returning farmland to forest and grassland in the ecotone between agriculture and animal husbandry areas in North China. - Journal of China Agricultural University 13(6): 6-10. 
[44] Tian, K., Zhao, Y., Xu, X., Huang, B. (2014): A meta-analysis of field experiment data for characterizing the topsoil organic carbon changes under different fertilization treatments in uplands of China. - Acta Ecologica Sinica 34(13): 3735-3743.

[45] Toohey, R. C., Boll, J., Brooks, E. S., Jones, J. R. (2018): Effects of land use on soil properties and hydrological processes at the point, plot, and catchment scale in volcanic soils near Turrialba, Costa Rica. - Geoderma 315: 138-148.

[46] Vohland, K., Schroth, G. (1999): Distribution patterns of the litter macrofauna in agroforestry and monoculture plantations in central Amazonia as affected by plant species and management: a section of Agriculture, Ecosystems \& Environment. - Applied Soil Ecology 13(1): 57-68.

[47] Wang, W. J., Qiu, L., Zu, Y. G., Su, D. X. (2011): Changes in soil organic carbon, nitrogen, $\mathrm{pH}$ and bulk density with the development of larch (Larix gmelinii) plantations in China. - Global Change Biology 17(8): 2657-2676.

[48] Wang, C., Liu, D., Bai, E. (2018): Decreasing soil microbial diversity is associated with decreasing microbial biomass under nitrogen addition. - Soil Biology \& Biochemistry 120: 126-133.

[49] Wei, S., Peng, G., Lu, L., Dai, Y., Zhang, K. (2014): Soil diversity as affected by land use in china: consequences for soil protection. - The Scientific World Journal ID: 913852.

[50] Xu, Q., Zhang, F., Xu, Z. Q. (2011): Some characteristics of Simpson index and the Shannon-Wiener index and their dilution effect. - Pratacultural Science 28(4): 527-531.

[51] Yang, Z. L. (2004): Advances in the research on returning farmland to forestry or pasture in China and the general approaches. - Forest Research 17(4): 512-518.

[52] Yin, X., Song, B., Dong, W., Xin, W., Wang, Y. (2010): A review on the eco-geography of soil fauna in China. - Journal of Geographical Sciences 20(3): 333-346.

[53] Yin, X., Qiu, L., Jiang, Y., Wang, Y. (2017): Diversity and spatial-temporal distribution of soil macrofauna communities along elevation in the Changbai Mountain, China. Environmental Entomology 46(3): 454-459.

[54] Zhang, L., Zhang, X., Cui, W. (2014): Relationship between land use pattern and the structure and diversity of soil meso-micro arthropod community. - Ecotoxicology 23(4): 707-717.

[55] Zhang, R., Zhao, X., Pu, C., Liu, S., Xue, J., Zhang, X., Chen, F., Zhang, H. (2015): Meta-analysis on effects of residue retention on soil $\mathrm{N}_{2} \mathrm{O}$ emissions and influence factors in China. - Transactions of the CSAE 31(22): 1-6.

[56] Zhao, L., Wu, W., Xu, X., Xu, Y. (2014): Soil organic matter dynamics under different land-use in grasslands in Inner Mongolia (northern China). - Biogeosciences 11(4): 56135637.

[57] Zhao, H., Sun, B., Lu, F., Wang, X. (2017): Meta-analysis on impacts of biochar on trace greenhouse gases emissions from staple crops in China. - Transactions of the CSAE 33(19): 10-16.

\section{APPENDIX}

[1] Abliz, O., Nurmammat, G., Tursun, A., Hajim, M., Wu, S. L. (2013): Community diversity and its seasonal dynamics of soil fauna in Fukang oasis of Xinjiang, Northwest China. - Chinese Journal of Ecology 32(6): 1412-1420.

[2] Anwar, T., Omar, A. (2008): Community structure of soil animals in different landscape in Changji city, Xinjiang China. - Ecology \& Environment 17(1): 344-349.

[3] Anwar, T., Yu, S. G. (2008): Distribution of soil macro-and meso-animal communities in the north suburbs of Urumqi. - Journal of Ecology \& Rural Environment 24(2): 36-40.

[4] Bao, Y. X., Cheng, H. Y., Ge, B. M. (2007): Soil macrofauna community in different using type of soils. - Journal of Zhejiang Normal University 30(2): 121-127. 
[5] Cheng, S., Fan, Y. L., Peng, B. X. (2014): Soil fauna feature of different soils in Wudang District. - Journal of Guizhou Normal College 30(3): 27-30.

[6] Dong, W. H., Li, X. Q., Song, Y., Wu, X. W., Liu, T. Z., Xu, X. H. (2017): The effect of highway on diversity of soil meso-microfauna in farmland and shelter forest. - Scientia Geographica Sinica 37(3): 473-48.

[7] Eziz, M., Abliz, O., Ablikim, S., Ubulkasim, A. (2015): The diversity and similarity of soil meso- and microfaunal community at different habitats in plain area of Ebinur lake basin, Xinjiang. - Journal of Arid Land Resources and Environment 29(6): 104-109.

[8] Gao, L. J., Hou, J. H., An, Z., Ma, D. X., Gao, B. J. (2013): Community structure of large size soil macrofauna in different land use types. - Pratacultural Science 30(7): 1111-1115.

[9] Ge, B. M., Kong, J. M., Cheng, H. Y., Zheng, X., Bao, Y. X. (2005): Community structure of soil macrofauna in different using types of soils in autumn. - Zoological Research 26(3): 272-278.

[10] Ge, B. M., Cheng, H. Y., Zheng, X., Kong, J. M., Bao, Y. X. (2005): Community structure and diversity of soil macrofauna from different urban greenbelts in Jinhua City, Zhejiang Province. - Biodiversity Science 13(3): 197-203.

[11] Ge, B. M., Zhang, D. Z., Tang, B. P., Zhou, C. L. (2014): Effect of land cover on biodiversity and composition of a soil macrofauna community in a reclaimed coastal area at Yancheng, China. - Turkish Journal of Zoology 38: 229-233.

[12] Ke, X., Liang, W. J., Yu, W. T., Xie, R. D., Weng, C. L., Yang, Y. M., Yin, W. Y. (2004): Community structure and seasonal change of soil micro-arthropodes in the Lower Reaches of Liaohe River Plain under different land utilization. - Chinese Journal of Applied Ecology 15(4): 600-604.

[13] Li, A. P. (2005): The distribution of soil animals in the land with different types of useful forms in Taiyuan. - Journal of Shanxi Teachers University 19(1): 84-87.

[14] Li, S. M., Ma, K. S., Li, J. P. (2008): Study on the biodiversity of soil fauna in different land use type. - Journal of Anhui Agricultural Sciences 36(2): 695-696, 744.

[15] Li, F. R., Liu, J. L., Liu, C. A. (2012): The combined effects of land cover change and management practices on soil microarthropod communities. - Journal of Desert Research 32(2): 340-350.

[16] Li, Q. F., Zhang, J. E., Qin, Z. (2012): Soil faunal community structure in winter season under various land use types in Guangzhou. - Chinese Journal of Eco-Agriculture 20(11): 1521-1526.

[17] Li, T., Liu, Y. Q., Guo, S. M., Ke, G. Q. (2012): Community traits of soil fauna in forestlands converted from cultivated lands in limestone red soil region of Ruichang, Jiangxi Province of China. - Chinese Journal of Applied Ecology 23(4): 910-916.

[18] Li, H. Y., Yin, X. Q., Ma, C. (2017): Ecological distribution of soil fauna communities in hilly regions of the Changbai Mountains relative to land use. - Acta Pedologica Sinica 54(4): 1018-1028.

[19] Li, F. R., Liu, J. L., Ren, W., Liu, L. L. (2018): Land-use change alters patterns of soil biodiversity in arid lands of northwestern China. - Plant \& Soil 428: 371-388.

[20] Lin, Y. H., Zhang, F. D., Zhang, J. Q., Ouyang, X. J. (2005): Preliminary investigation on temporal and spatial variation of structure of soil fauna community in different natural vegetations of Dinghushan. - Acta Ecologica Sinica 25(10): 2616-2622.

[21] Lin, L. W., Zhong, J. H., Tan, J. (2012): Influence of different land use types on the soil fauna diversity. - Ecology and Environmental Sciences 21(10): 1678-1682.

[22] Liu, X. M. (2008): The features of macrofauna community biodiversitiy under different habitats in horqin sandland. - Journal of Inner Mongolia Normal University 37(1): 98103.

[23] Liu, X. M., Men, L. N. (2009): Effects of grassland restoration from cropland on soil macrofaunal community in Wuchuan county, Inner Mongolia. - Chinese Journal of Applied Ecology 20(8): 1965-1972. 
[24] Liu, Y., Zhang, A., Yan, Y. (2011): Diversity of soil animal community under different land-use types in chongming island. - Journal of Fudan University 50(3): 288-295.

[25] Liu, R. T., Zhao, H. L., Zhao, X. Y., Drake, S. (2011): Facilitative effects of shrubs in shifting sand on soil macro-faunal community in Horqin Sand Land of Inner Mongolia, Northern China. - European Journal of Soil Biology 47(5): 316-321.

[26] Liu, R. T., Zhu, F., Zhao, H. L. (2013): Effects of land use/cover changes on soil macrofaunal community in agro-pastoral transitional zone, Northern China. - Acta Agrestia Sinica 21(4): 643-649.

[27] Ma, H. B., Liu, H. Q. (2012): Characteristics of soil fauna communities in different land use patterns in the Lhasa River basin. - Journal of Northeast Normal University 44(2): 84-90.

[28] Ming, F. B., Men, L. N., Liu, X. M. (2013): Effects of different management modes of grassland after returned from cropland on meso-and micro-faunal communities in Wuchuan County of Inner Mongolia, North China. - Chinese Journal of Ecology 32(7): 1838-1843.

[29] Nurmammat, G., Abliz, O., Nurmammat, N. (2013): Community diversity of soil macrofauna at different habitats in the Yamalik Mountain from Urumqi. - Journal of Xiamen University 52(4): 569-573.

[30] Nurmammat, G., Abliz, O., Anwar, O. (2013): Study on the diversity of soil meso-and micro-fauna in Yamalik Mountain from Xinjiang. - Journal of Huazhong Normal University 47(1): 91-96.

[31] Shen, N. J., Ye, F. C., Dong, D. P. (2011): Study on soil animal resources of seven different ecosystems in Xuchang. - Journal of Xuchang University 30(2): 41-44.

[32] Sulayman, A., Omar, A., Eziz, M. (2014): The community structure of soil meso- and micro- fauna at different habitats in plain area of Ebinur lake, Xinjiang. - Journal of Arid Land Resources \& Environment 28(11): 103-110.

[33] Wang, G. L., Wang, Y., Han, L. L., Zhang, M. W., Li, B. (2005): Soil animal communities of variously utilized in the Dongting Lake region. - Acta Ecologica Sinica 25(10): 2629-2636.

[34] Wang, J. F., You, W. H. (2007): Community structure of soil meso-and microinvertebrate in different habitats in Shanghai. - Ecology \& Environment 16(4): 12381243.

[35] Wang, Y. D., Zheng, Z. C., Li, T. X., Shen, Y. (2016): Community structure and dynamic changes of soil fauna in farmland-transformed tea plantation. - Bulletin of Soil \& Water Conservation 36(2): 48-53.

[36] Wei, S. G., Peng, G., Lu, L., Dai, Y. J. (2014): Soil diversity as affected by land use in china: consequences for soil protection. - The Scientific World Journal. doi.:10.1155/2014/913852.

[37] Wu, D. H., Zhang, B., Cheng, P. (2006): Community structure and composition of soil macrofauna under different land use in Changchun City. - Acta Zoologica Sinica 52(2): 279-287.

[38] Wu, P. F., Yu, X. F., Yang, D. X. (2009): Comparison of soil fauna community characters of three different land utilizations in the suburbs of Chengdu City. - Journal of Southwest University for Nationalities 35(5): 1006-1012.

[39] Wu, Y. H., Cai, Q. N., Lin, C. W., Chen, Y. B. (2009): Community structure of soil macrofauna under different land-use systems in the purple hilly areas of Sichuan Basin. Chinese Journal of Eco-Agriculture 17(1): 34-40.

[40] Wu, Y. H., Cai, Q. N., Lin, C. W., Zhao, X. (2009): Community structure of soil mesofauna under different land use patterns in purple soil hilly area of Sichuan Basin. Chinese Journal of Ecology 28(2): 277-282.

[41] Wu, Y. H. (2012): Effect of different land-use systems on soil animal diversity. - Journal of Anhui Agricultural Sciences 40(17): 9270-9273, 9313. 
[42] Xiang, C. G., Song, L. H., Zhang, P. J., Pan, G. X. (2011): The case study on soil fauna diversity in different ecological system in Shilin national park, Yunnan, China. - Acta Carsologica 32(2): 187-194.

[43] Yang, D. Q., Gao, J., Han, H. X. (2003): The distribution of urban soil animals in the land with different types of utilization. - Journal of Shanghai Teachers University 32(4): 8692.

[44] Yang, L. H., Shi, H. Y., You, Z. Q. (2015): Effect of different land use types on soil macrofauna community structure. - Journal of Sichuan Agricultural University 33(2): 208-214.

[45] Yang, B. L., Zhang, W. W., Fan, H. (2017): Community structure of soil fauna under different land use types in the coastal area of Northern Jiangsu Province. - Journal of Nanjing Forestry University 41(6): 120-126.

[46] Yin, X. Q., Wang, H. X., Zhou, D. W. (2003): Characteristics of soil animals' communities in different agricultural ecosystem in the Songnen Grassland of China. Acta Ecologica Sinica 23(6): 1071-1078.

[47] You, W. Z., Liu, M. G., Zeng, D. H. (2006): Diversity of large animals in top soil layers on forest and grass scenic borders in Loess hilly areas. - Liaoning Forestry Science \& Technology 1: 1-3.

[48] Yuan, J. R., Zhu, X., Zhu, Y. A., Lin, Z. (2006): Calcareous soil's faunal diversity in different habitats of Yongzhou, Hunan Province. - Chinese Journal of Ecology 25(9): 1073-1076.

[49] Zhai, Y. X., Zang, J. C., Su, C. (2017): Effects of different tillage methods Linzhi City on community characteristics of soil fauna. - Southwest China Journal of Agricultural Sciences 30(1): 141-147.

[50] Zhang, X. P., Li, C. Y., Yin, X. Q. (1999): Relation between soil animals and nutrients in the differently used forest lands. - Chin. J. Appl. Environ. Biol. 5(1): 26-31.

[51] Zhang, Z. Y., Zhang, L., Li, Y. H., He, X. L. (2005): Study on the diversity of soil macro fauna in different habitats in shilin karsts of Yunnan Province, China. - Forest Research 18(6): 701-705.

[52] Zhang, X. P., Zhang, W., Cao, H. C. (2006): Geo-ecology of soil fauna in different tundras in daxinganling mountains. - Acta Pedologica Sinica 43(6): 996-1003.

[53] Zhang, L. L., Bao, Y. X., Hu, Z. Y., Sun, B., Zhao, Q. Y., Xu, J. (2009): Community structure of soil fauna in different cover type of river source wetland in autumn. - Journal of Zhejiang Normal University 32(4): 453-459.

[54] Zhang, J. E., Qin, Z., Li, Q. F. (2011): Clustering and ordination of soil animal community under different land-use types. - Chinese Journal of Ecology 30(12): 28492856.

[55] Zhang, L. M., Zhang, X. P., Cui, W. (2014): Relationship between land use pattern and the structure and diversity of soil meso-micro arthropod community. - Ecotoxicology 23(4): 707-717.

[56] Zhao, Z. C., Xiong, K. N., Chen, H., Zhang, F. T. (2010): Analysis on soil animal community structure of different land utilization patterns in Qingzhen City. - Guizhou Agricultural Sciences 38(6): 116-120.

[57] Zhao, H. L., Liu, R. T., Zhou, R. L. (2012): Effects of changes in land use on soil macroarthropod communities in Horqin sand land. - Acta Pedologica Sinica 50(2): 413-418.

[58] Zhao, H. L., Zhang, T. H. (2013): Effects of land cover changes on soil arthropod community in Horqin sand land, China. - Journal of Life Sciences and Technologies 1(2): $112-117$.

[59] Zhou, J. H., Zhu, Y. H., Gao, T. T. (2015): Community Structure of Soil Macrofauna in Different Land Use Types. - Environmental Science \& Management 40(12): 150-154.

[60] Zhu, L. X., Chen, Q. S., Yu, S. C., Zheng, L. Z., Chen, S. X. (2010): Study on the composition and diversity of soil animal community in Zhangzhou City. - Journal of Zhangzhou Normal University 23(2): 113-118. 